\title{
The Role of Beauty in Donation Crowdfunding
}

\author{
Jooyoung Park \\ Peking University HSBC Business School \\ jpark@phbs.pku.edu.cn
}

\author{
Keongtae Kim \\ CUHK Business School, Chinese University of Hong Kong \\ keongkim@cuhk.edu.hk
}

\begin{abstract}
This study examines the effect of physical attractiveness of recipients on donation decisions in a prosocial microlending market by combining both archival data analysis and a controlled experiment. We show that attractiveness of female recipients matters to donors. More attractive recipients tend to have a larger share of male donors, implying that male (female) donors are more (less) favorable toward those recipients. On the contrary, the attractiveness of male recipients did not change the composition significantly. These findings have implications for the beauty effect in crowd-driven platforms and provide guidance for recipients seeking donation from crowds.
\end{abstract}

\section{Introduction}

Online crowdfunding has facilitated small financial transactions between entrepreneurs and funders and supported various types of ventures ranging from high potential technology to creative projects. One form of popular crowdfunding is prosocial microlending, where lenders make loans to small businesses mostly in developing countries. On prosocial microlending platforms lenders typically do not receive any interest rate and do so to help alleviate world poverty. Thus, such microlending is considered prosocial in which lenders evaluate individual loans on not only traditional lending criteria but also prosocial, charitable cues [12].

While online peer-to-peer lending (P2P) platforms like Prosper typically provide lenders with a variety of information about recipient creditworthiness, online prosocial lending platforms like Kiva do not provide such information to lenders because most of the recipients on the platforms are from developing countries lacking formal banking systems and an access to formal credit systems. Along with prosocial motivations of lenders, this suggests that donors may make decisions based on subjective judgments [2]. Studies showed that donors on microlending platforms tend to prefer recipients who are socially similar to themselves, and are sensitive to the language of loan requests $[2,12]$. Joining a lending team also promotes prosocial lending in online microlending [1]. While these studies advance our understanding of what affects prosocial lending decisions in online microfinance, we know little about whether the physical attractiveness of recipients influences prosocial donation decisions. Furthermore, little is known about whether the effect of recipients' physical attractiveness is different between male and female donors. If so, what is the mechanism behind this phenomenon?

Although there has been little research on the effect of physical attractiveness of recipients in online prosocial microlending, some evidence suggests that physical attractiveness plays a role in various contexts, including P2P lending [43], entrepreneurial pitch [9], and offline charitable giving [30]. Research has shown that people are generally biased toward attractive recipients. It further suggests that the bias could depend on the gender of recipients and investors. Nonetheless, we also see mixed findings regarding the beauty effects in prior research. Brooks et al. (2014) did not find such benefits of physical attractiveness in an entrepreneurial pitch. This suggests that we cannot simply generalize prior findings to online prosocial microlending context, which is the primary focus of the present research.

To examine the beauty effects and gender differences in an online prosocial microlending context, we combined experimental data and empirical transaction data from a real online prosocial microlending platform, Kiva.org. After its establishment in October 2005, Kiva has grown as one of the most successful prosocial microlending platforms especially for people in developing countries. We confine our sample to loans from Health category initiated in 2017 on the platform. People in this category generally seek financial help to obtain the medicine and healthcare services they need. After dropping group loans and loans with missing values, we ended up having 3,191 loans attracting around US 2.6 million dollars from over 76,600 donors. We conducted loanlevel analyses to show the effect of physical attractiveness on donation decisions. To replicate the findings from the empirical transaction data, we ran an experiment using Amazon Mechanical Turk (MTurk) workers. 
Using the archival data from Kiva, we found that the physical attractiveness of recipients does matter to donors but in a nuanced way. When a female recipient is more attractive, her loan is associated with a larger share of male donors. This implies that male (female) donors are likely to be more (less) favorable to attractive female recipients in need. On the contrary, the physical attractiveness of male recipients does not influence the share of female or male donors. Our experiment confirms the findings from the archival data.

This study provides several contributions to the literature. First, our study is the first to provide systematic evidence of the significant effect of physical attractiveness in crowdfunding. Although few studies have examined physical attractiveness in crowdfunding, they did not consider the heterogeneous effects by the gender of both recipients and donors [42,43]. Considering both recipients and donors allows us to show rather complex effects of beauty on donation decisions in online crowdfunding. More broadly, our study highlights the beauty discount effect which has been rarely reported in the literature. To our knowledge, prior studies examining the beauty effect generally show the beauty premium, favorable benefits to more attractive individuals, in various contexts [30,32]. We extend this literature by showing not only a boundary condition, the gender of donors, and a negative effect of beauty for female donors in donation-based crowdfunding. Finally, our study provides practical implications for potential recipients and platform providers. For instance, our results suggest recipients need to use different appeals toward male and female donors.

\section{Literature review 2.1. Gender differences in helping}

Research in various disciplines, including economics, social psychology, sociology, and marketing has examined individuals' charitable giving. Bekkers and Wiepking [7] have reviewed this large body of research and identified several drivers of philanthropy such as need for help, positive emotion, and efficacy. According to their review, awareness or perceived need from the recipients is a first prerequisite for philanthropy [7]. Research in social psychology has observed the positive association between the level of need for help and the likelihood of help in various contexts including monetary donation [7,48]. More important, research has shown that subjective perceptions of need rather than objective need result in philanthropy [54].

People also help others because giving generates positive emotional responses and reduces negative feelings like guilt and aversive arousal. Batson and Shaw [6] showed that helping others causes positive psychological outcomes for the helper, "empathic joy." Neuropsychological studies also provide supporting evidence that donation evokes neural activities in areas in our brain that are linked to reward processing [26]. Economic models also consider these psychological benefits and labelled them as "warm glow" or "joy of giving" [3]. Together, these prior studies indicate that giving can provide pleasurable emotional consequences, motivating individuals to donate or help others. Another driver of philanthropy is efficacy, which refers to the perception of donors that their help or contribution can make a difference to the individuals or the cause that they support. Research has shown that people tend to give less when they perceive that their contributions would not make a difference $[17,41]$.

Research indicates that gender roles and gender stereotypes are important determinants of gender differences in helping behavior [20]. Historically, female gender roles expect females to perform various forms of helping in family and help others in various social contexts [8]. Male gender roles also promote helping but other forms of helping. One of such form is heroic behavior, altruistic acts of protecting others from harm at the risk to oneself [20]. For instance, heroism motivates men to help others to a greater extent as the amount of danger inherent in helping increases. Related to heroism, chivalry is also encouraged by the male gender roles. Chivalry motivates men to protect the weak and defenseless, especially women [10]. Thus, in the context of philanthropy, men are more likely to help women in situations involving chivalrous protectiveness or civility.

Another stream of research suggests that gender differences in charitable giving are the outcomes of inherent motivations. For instance, women are more oriented toward caring and responsibility [20]. Studies showed that women are generally rated more favorably than men, not only on helpfulness, but also on kindness and the ability to devote oneself solely to benefit others [46,51]. In addition, compared with men, women are more likely to show perspective taking, which allows them to better understand others' emotions and situations [52]. Some research directly tested gender differences in the motivations for charitable giving. Willer et al. [56] found that framing a charitable appeal to emphasize self-interest increases donation from men relative to women, suggesting a higher self-oriented motivation of men than women. Similarly, Chang and Lee [14] found that egoistic appeals increase men's donation intention, whereas altruistic charitable appeals increase women's donation. Regarding efficacy, one of the key mechanisms of philanthropy (Bekkers \& Wiepking 2011), research suggests that men place a 
greater emphasis on efficacy than women. Because women show higher dispositional empathy than men, they are more likely to distribute their resources equally to a larger number of recipients. In contrast, men are more strategic in charitable giving and tend to focus on a smaller group of recipients [15]. This prior work implies that egoistic motivation is the primary driver of men's donation, whereas altruistic motivation is the main driver of women's donation.

Despite the significant growth of online donationbased crowdfunding markets, there has been limited research on individuals' donation behavior as well as gender differences. Burtch et al. [13] observed a crowdout effect of others' contributions in a crowdfunding market for online journalism projects, showing the existence of altruistic motivation of crowdfunders. Burtch and Chan [11] examined a crowdfunding market for medical expenses and found that crowdfunding reduces personal medical bankruptcy rates. Few studies examined donation behaviors in online microlending markets and examined several factors influencing individuals' donation behavior, including the social, cultural similarity between donors and recipients $[12,24]$, the language of loan requests [34,36], and joining a lending team [1].

Important, to the best of our knowledge, no study has examined gender differences in donation behaviors in the context of crowdfunding. The literature has focused mostly on the gender of recipients, not funders. They showed that women generally get more benefits from crowdfunding in terms of funding success and financial cost $[40,43]$. Nonetheless, those studies are based on crowdfunding markets where funders have strong financial incentives. Thus, those findings may not be generalizable to donation-based crowdfunding, which is the primary context of the present research. Moreover, there is much room to advance our knowledge on gender differences in helping behavior in both offline and online contexts.

\subsection{Beauty effects and gender difference}

Attractiveness has been found to have a profound impact on how people perceive others [18,21]. Attractiveness is generally associated with positive stereotypical information, which typically comes to mind spontaneously upon encountering others [32,39]. Prior research observed the positive biases toward attractive faces in various dimensions of social life. For example, attractive people tend to be perceived as being more competent, and as such, they tend to receive higher salaries and have higher chances of mating success $[18,19,31]$. Both evolutionary social psychology and neuroscience have also provided supporting evidence. Evolutionary social psychology has suggested that facial attractiveness indicates the reproductive capacities and genetic fitness of potential mates $[22,45]$. Although women are also intrinsically attracted to beauty, research observed that men tend to value physical attractiveness more highly than women do [33]. For instance, a study showed that men are willing to wait longer, exchange more money, and devote more effort than females for the opportunity to look at attractive opposite-sex faces [27].

More relevant to the present research, Landry et al. [30] examined the impact of physical attractiveness and solicitation using a field experiment. They found that the physical attractiveness of female solicitors leads to more charitable giving especially from male donors. On the contrary, in a setting of entrepreneurial finance, Brooks et al. [9] revealed that investors prefer to invest in male entrepreneurs, especially who are physically attractive. Few studies in crowdfunding contexts examined the beauty effect and its interaction with gender. Ravina [43] showed that attractive recipients are more likely to get a loan, and given a loan, especially female recipients pay less in an online peer-to-peer lending market. In an online crowdfunding platform, Raihani and Smith [42] found that men tend to show competitive donation toward attractive female recipients at the existence of other male counterparts' large donation, while females do not respond significantly to the physical attractiveness of male recipients. Although there have been few attempts to examine the interaction of gender and beauty effects, previous research provides inconsistent findings across various contexts, suggesting the importance of systematic empirical research to test beauty effects and their interaction with gender of donors as well as recipients.

\section{Hypothesis development}

Facial attractiveness automatically raises individuals' attention and plays important roles in impression formation about the target person $[4,53]$. People tend to judge attractive faces more positively, perceiving them as being socially more competent, more intelligent, and even biologically healthier [19,23]. For instance, attractive individuals could be more likely to have effective social interactions and are likely to be influential in their social interactions. Research in neuroscience has also provided evidence supporting the positive relationship between attractiveness and goodness with respect to a physiological basis. Research has revealed that the regions of the brain linked to judgments of beauty overlap with the regions related to morality, indicating a positive bias toward beauty and goodness [38,50]. Although there is a consensus that attractiveness produces positive biases, the outcomes of 
beauty in the context of charitable giving are rather mixed.

Some studies examining recipient beauty and charitable giving showed that donors tend to give more to less attractive, needier recipients [23]. Some research supports beauty premium, the positive impact of attractiveness on charitable giving [16,35]. Consistent with prior research on gender differences in charitable giving, we expect that women are more altruistically motivated and more concern about neediness of the recipients than men [14]. Given that beauty is positively associated with social competence and negatively with neediness, women would perceive less neediness and empathy toward more attractive recipients and would give less to them than less attractive recipients. In contrast, compared with women, men are more sensitive, attentive, and tend to assign higher values to attractive targets, especially female targets [27,33]. As a consequence, men tend to positively react to more attractive females than less attractive females [4,30]. Furthermore, the positive bias of beauty is also closely related to pleasure. Given that men are more likely to donate due to egoistic motivations rather than altruistic motivation, male donors would be more likely to rely on intuitive preferences and donate to more attractive recipients than less attractive recipients. Together, we propose our first hypothesis as follows:

H1. Male donors will be likely to help more attractive female recipients, whereas female donors will be more likely to help less attractive female recipients.

Research has documented that men and women asymmetrically respond to the attractiveness in evaluating a target person. Although some studies showed that attractiveness matters equally for male and female [25,32], majority of research on the positive bias of physical attractiveness supports that the bias has larger impacts on women than men. For instance, BarTal and Saxe [5] indicate that the impact of physical attractiveness matters more for women relative to men because men tend to focus more on physical attractiveness when encountering others than women do. Even in contexts other than dating or mate selection, evidence suggests a greater importance of attractiveness for women than for men. Kaplan [29] compared ratings of an essay written by an attractive or an unattractive author between male and female evaluators. They revealed the positive bias toward attractive authors occurs only for female authors but not for male authors. In an online lending platform, Jenq et al. [28] also found that female recipient's physical attractiveness matters more than male recipient's in affecting individuals' decisions. Consistent with prior research, we expect that the effect of facial attractiveness would be significant for female recipients but not for male recipients.
H2. The impact of facial attractiveness on donation will be more likely to occur for female recipients than for male recipients.

We tested our hypotheses by combining an empirical data from a real online prosocial microlending platform and experiment data. We first tested whether the asymmetric beauty effects for male versus female donors exist (H1) and whether such effects are more pronounced for female recipients than male recipients (H2) using the empirical data.

\section{Study from Kiva data 4.1. Study context and variables}

We first gathered information on prosocial lending activity from Kiva, an online crowdfunding platform which facilitates prosocial lending between individuals starting from 2005. On Kiva, individual recipients can initiate loan campaigns to solicit lending. A typical loan campaign page contains recipients' information, including their names, location, and photos, and some loan characteristics (e.g., loan amount, loan purpose, and loan repayment term). Information about the field partner that sourced the loan such as its name and the performance of all the loans managed by the field partner is also collected. Field partners are crucial on the platform because they not only help Kiva reach more recipients, some of which living in remoted places in the world, but they are also the ones to source loans, provide services to recipients, and administer loans. A campaign page presents information about donors. For example, which donors pledged to donate to the campaign. Importantly, individual kiva donors do not receive interest from loans they support on Kiva.

We limited our sample to loans from 'Health' category initiated in 2017 on the platform. People in this category generally seek financial help to obtain the medicine and healthcare services they need. We included only individual loans with one recipient, because multiple recipients are highly likely to have multiple people in profile images, thus making unnecessarily difficult for us to examine the beauty effect of recipients. Over $93 \%$ of loans are individual loans in our sample. In the same reason, we dropped individual loans with multiple faces in their profile image. We further dropped 60 loans because profile images in those loans were not very clear so did not allow us to extract beauty scores of people in those images. Finally, we dropped loans with missing values. We ended up having a total number of 3,191 loans attracting around 2.6 million dollars from over 76,600 donors.

We measured beauty scores of loan recipients using their profile image. We use the Face Analyze API of 
Megvii Technology Company to construct beauty scores of faces. The tool detects and locates human faces within an image, and returns high-precision face bounding boxes. It also allows us to extract information not only about beauty but also about age and facial expression. While each face in an image has two beauty scores, one from female evaluators and another from male evaluators, we use the average beauty score. We also asked people on Mturk to evaluate 675 profile images in our sample and found that the correlation of beauty scores between the face recognition tool and the Mturk is 0.48 , validating our main beauty scores.

We created a dependent variable to test how the beauty of recipients affect donors' decisions and whether the effect varies by genders of recipients and donors. The dependent variable is the share of female donors in a loan. Even if the gender of recipients is provided by the platform, the information about the gender of donors is not. Thus, we exploited profile images of donors and donor names to extract gender information using machine learning techniques, although we note that over $21 \%$ of donors are anonymous. First, regarding $40 \%$ of donors with profile images we used the images to extract the gender of the donors. Again, we use the Face Analyze API to identify the gender of donors. Based on the recipients whose gender is known to us, the accuracy of the tool for the identification of the donor gender is around $91 \%$. The remaining $60 \%$ of donors do not have profile images so we use their names after cleaning the names. We used the Wikipedia corpus database, which contains more than 1 million records. It is known that this sample is quite representative to the population. We then randomly divided our data set into a training set $(80 \%)$ and a test set $(20 \%)$. Two different predictive models (Support Vector Machine (SVM) and N-Gram Model were tested to classify the gender by full name. We chose the SVM Model with a better accuracy of $90 \%$.

We added relevant loan- and recipient-specific characteristics that are expected to influence donation decisions from prior studies on Kiva [2,24]. We included loan size (i.e., the amount of the requested loan), loan term (i.e., the loan payment terms in months), the recipient gender (provided by Kiva), and two dummies for repayment interval. We also include the average difference in age between the recipient and its donors to control for the effect of age similarity. This is especially important in our study because donors may be more likely to donate to recipients of similar ages and at the same time age may affect the perception of donors about the physical attractiveness of recipients. For the recipient age, we could get the correct age for $75 \%$ of recipients based on their project description. Age or birth date is mentioned in their project description. For the remaining recipients we use the extracted age from their profile images. For the donor age, we have the estimated age for $40 \%$ of donors with profile images. Also, we included field partner fixed effects to control for field partner-specific effects. Several studies used risk rating associated with each field partner given by Kiva. Given this rating does not change in our data, having field partner fixed effects should be more conservative. Some loans do not have an associated field partner so we added a dummy for loans with no field partner. We did not include borrower country characteristics used in some prior studies because we focus on the short term period of year 2017. Moreover, country fixed effects were superseded by field partner fixed effects, because field partners in our sample worked for one country. Finally, we included month fixed effects. Tables 1 and 2 present the definitions and descriptive statistics, respectively, of key variables.

\subsection{Empirical implementation}

Our model is as follows:

$$
L_{i}=\phi+\mathbf{X}_{i} \boldsymbol{\beta}+\pi_{f(i)}+\rho_{t(i)}+\epsilon_{i}
$$

where the subscript represents loan i. $\boldsymbol{L}_{\boldsymbol{i}}$ is the share of female donors in loan i. $\mathbf{X}_{\boldsymbol{i}}$ represents loan and recipient characteristics. $\boldsymbol{\pi}_{\boldsymbol{f}(\boldsymbol{i})}$ refers to fixed effects of field partner $\mathrm{f}$. We also included monthly fixed effects (based on loan posting date) $\boldsymbol{\rho}_{\boldsymbol{t}(\boldsymbol{i})}$ to control for time-specific variations. Finally, $\boldsymbol{\epsilon}_{\boldsymbol{i}}$ is a random error term. We use robust standard errors. Because our dependent variable is the share bounded between 0 and 1, we conducted estimates from generalized linear models (GLMs) with logistic link.

Table 1. Definition of Variables

\begin{tabular}{|l|l|}
\hline Variable & Definition \\
\hline Share of female donors & Share of female donors in a loan \\
\hline Beauty score & $\begin{array}{l}\text { A score of facial attractiveness } \\
\text { based on the profile image of a } \\
\text { recipient }\end{array}$ \\
\hline Female recipient & $\begin{array}{l}1 \text { if a recipient is a female and 0 } \\
\text { if a recipient is male }\end{array}$ \\
\hline Loan size & $\begin{array}{l}\text { The total amount of the } \\
\text { requested loan }\end{array}$ \\
\hline Loan term & $\begin{array}{l}\text { The loan repayment term in } \\
\text { months }\end{array}$ \\
\hline Age different & $\begin{array}{l}\text { The average difference in age } \\
\text { between the recipient and her } \\
\text { donors }\end{array}$ \\
\hline No field partner & $\begin{array}{l}1 \text { if a loan does not have any } \\
\text { associated field partner and } 0 \\
\text { otherwise }\end{array}$ \\
\hline
\end{tabular}


Table 2. Summary Statistics

\begin{tabular}{|c|c|c|c|c|c|c|c|c|}
\hline Variable & $\begin{array}{l}\text { Mea } \\
\mathrm{n}\end{array}$ & SD & (2) & (3) & (4) & (5) & (6) & (7) \\
\hline $\begin{array}{l}\text { Share of } \\
\text { female } \\
\text { donors } \\
\text { (1) }\end{array}$ & 0.51 & 0.17 & $\overline{0}-\overline{0}$ & 0.07 & 0.01 & 0.09 & 0.01 & 0.05 \\
\hline $\begin{array}{l}\text { Beauty } \\
\text { score (2) }\end{array}$ & $\begin{array}{l}48.3 \\
6 \\
\end{array}$ & $\begin{array}{l}11.8 \\
3 \\
\end{array}$ & 1 & $-\overline{0.21}$ & 0.06 & 0.03 & 0.12 & $\overline{-} .01$ \\
\hline $\begin{array}{l}\text { Female } \\
\text { recipient } \\
(3)\end{array}$ & 0.64 & 0.48 & & 1 & 0.01 & $\begin{array}{l}- \\
0.09\end{array}$ & $\overline{-}-$ & 0.05 \\
\hline $\begin{array}{l}\text { Loan } \\
\text { size (4) }\end{array}$ & 881 & $\begin{array}{l}161 \\
1 \\
\end{array}$ & & & 1 & 0.20 & $\overline{-}-\overline{0}$ & 0.24 \\
\hline $\begin{array}{l}\text { Loan } \\
\text { term (5) }\end{array}$ & $\begin{array}{l}17.2 \\
9\end{array}$ & 6.12 & & & & 1 & $-\overline{0}$ & 0.12 \\
\hline $\begin{array}{l}\text { Age } \\
\text { differen } \\
\text { ce (6) }\end{array}$ & $\begin{array}{l}13.7 \\
4\end{array}$ & 9.68 & & & & & 1 & $-\overline{0.02}$ \\
\hline $\begin{array}{l}\text { No field } \\
\text { partner } \\
(7)\end{array}$ & 0.01 & 0.10 & & & & & & 1 \\
\hline
\end{tabular}

\subsection{Results}

To examine the effect of facial attractiveness on donation, we conducted a series of regressions. Column 1 of Table 3 reports GLM estimates with control variables and fixed effects for all the loans. Our coefficient of interest (i.e., beauty score) is negative and highly significant for our dependent variable, the share of female donors. This implies that a higher beauty score of recipients is negatively associated with the share of female donors. When a recipient has better facial attractiveness, this should lead to more male and/or fewer female donors. Regarding some control variables, we found that female recipients tend to attract proportionally more female donors, thus suggesting homophily behavior in the prosocial lending market. We also found that loans with longer terms tend to have proportionally more female donors.

We now break down recipients into female and male recipients. Column 2 shows that the negative effect of beauty score on the share of female donors is even stronger in the statistical significance and the magnitude. This finding is consistent with H1. The coefficient implies that a one standard deviation increase in beauty score (i.e., an increase of 11.8) translates on average into a $1.7 \% \mathrm{p}$ decrease in the share of female donors in a loan, which is economically significant. On the contrary, when we confined to male recipients, we did not observe any significant, negative effect of facial attractiveness on the share of female donors, suggesting that the facial attractiveness of male recipients have a similar, if any, effect on male and female donors. Columns 2 and 3 together support H2. In column 4 we use the interaction term between beauty score and the gender to test $\mathrm{H} 2$, which is still supported. We also use log of the number of female or male donors as a dependent variable. The negative effect is driven by both male donors' propensity to support more attractive female recipients and female donors' reluctance to support more attractive female recipients. In addition, we conducted another set of analyses with funding success as an additional dependent variable and found that beauty is not related to funding success. The two results are not reported here due to the page limit but available upon request. We next turn to only young recipients below age of 42 (i.e., median age) in columns $5-8$, because the beauty effect may be more relevant for young recipients. Our findings are qualitatively the same.

Table 3. Recipient Beauty and Share of Female Donors

\begin{tabular}{|c|c|c|c|c|c|c|c|c|}
\hline & $(1)$ & $(2)$ & $(3)$ & $(4)$ & $(5)$ & $(6)$ & $(7)$ & $(8)$ \\
\hline & \multicolumn{4}{|c|}{ All } & \multicolumn{4}{|c|}{ Borrowers with age of $<=42$} \\
\hline & All & $\begin{array}{l}\text { Female } \\
\text { recipient }\end{array}$ & $\begin{array}{c}\text { Male } \\
\text { recipient }\end{array}$ & All & All & $\begin{array}{l}\text { Female } \\
\text { recipient }\end{array}$ & $\begin{array}{c}\text { Male } \\
\text { recipient }\end{array}$ & All \\
\hline & $\begin{array}{c}\text { Share of } \\
\text { female } \\
\text { donors }\end{array}$ & $\begin{array}{c}\text { Share of } \\
\text { female } \\
\text { donors }\end{array}$ & $\begin{array}{c}\text { Share of } \\
\text { female } \\
\text { donors }\end{array}$ & $\begin{array}{c}\text { Share of } \\
\text { female } \\
\text { donors }\end{array}$ & $\begin{array}{c}\text { Share of } \\
\text { female } \\
\text { donors }\end{array}$ & $\begin{array}{c}\text { Share of } \\
\text { female } \\
\text { donors }\end{array}$ & $\begin{array}{c}\text { Share of } \\
\text { female } \\
\text { donors }\end{array}$ & $\begin{array}{c}\text { Share of } \\
\text { female } \\
\text { donors }\end{array}$ \\
\hline $\begin{array}{l}\text { Beauty } \\
\text { Score (BS) } \\
\text { Female }\end{array}$ & $\begin{array}{c}-0.004 * * * \\
(0.001)\end{array}$ & $\begin{array}{c}-0.005 * * * \\
(0.001)\end{array}$ & $\begin{array}{c}-0.002 \\
(0.002)\end{array}$ & $\begin{array}{l}-0.002 \\
(0.002)\end{array}$ & $\begin{array}{c}-0.004 * * \\
(0.002)\end{array}$ & $\begin{array}{c}-0.005^{* *} \\
(0.002)\end{array}$ & $\begin{array}{l}-0.002 \\
(0.003)\end{array}$ & $\begin{array}{l}-0.003 \\
(0.002)\end{array}$ \\
\hline $\begin{array}{l}\text { Recipient } \\
\text { (FR) } \\
\text { BS*FR }\end{array}$ & $\begin{array}{c}0.117 * * * \\
(0.027)\end{array}$ & & & $\begin{array}{c}0.282 * * * \\
(0.105) \\
-0.003 * \\
(0.002)\end{array}$ & $\begin{array}{c}0.083 * * \\
(0.036)\end{array}$ & & & $\begin{array}{c}0.209 \\
(0.175) \\
-0.002 \\
(0.003)\end{array}$ \\
\hline Loan size & $\begin{array}{c}-0.000 \\
(0.000)\end{array}$ & $\begin{array}{l}-0.000 \\
(0.000)\end{array}$ & $\begin{array}{c}-0.000 \\
(0.000)\end{array}$ & $\begin{array}{c}-0.000 \\
(0.000)\end{array}$ & $\begin{array}{c}-0.000 \\
(0.000)\end{array}$ & $\begin{array}{c}0.000 \\
(0.000)\end{array}$ & $\begin{array}{c}-0.000 \\
(0.000)\end{array}$ & $\begin{array}{l}-0.000 \\
(0.000)\end{array}$ \\
\hline Loan term & $\begin{array}{c}0.009 * * * \\
(0.003)\end{array}$ & $\begin{array}{c}0.006 \\
(0.004)\end{array}$ & $\begin{array}{c}0.015^{* * * *} \\
(0.005)\end{array}$ & $\begin{array}{c}0.009 * * * \\
(0.003)\end{array}$ & $\begin{array}{c}0.006 \\
(0.004)\end{array}$ & $\begin{array}{c}0.002 \\
(0.006)\end{array}$ & $\begin{array}{c}0.011 \\
(0.007)\end{array}$ & $\begin{array}{c}0.006 \\
(0.004)\end{array}$ \\
\hline $\begin{array}{l}\text { Age } \\
\text { difference }\end{array}$ & $\begin{array}{c}0.001 \\
(0.001)\end{array}$ & $\begin{array}{c}0.002 \\
(0.002)\end{array}$ & $\begin{array}{c}-0.000 \\
(0.002)\end{array}$ & $\begin{array}{c}0.001 \\
(0.001)\end{array}$ & $\begin{array}{c}0.002 \\
(0.002)\end{array}$ & $\begin{array}{c}0.003 \\
(0.003)\end{array}$ & $\begin{array}{c}-0.002 \\
(0.003)\end{array}$ & $\begin{array}{c}0.002 \\
(0.002)\end{array}$ \\
\hline
\end{tabular}




\begin{tabular}{lcccccccc} 
Controls & Yes & Yes & Yes & Yes & Yes & Yes & Yes & Yes \\
$\begin{array}{l}\text { Field partner } \\
\text { FE }\end{array}$ & Yes & Yes & Yes & Yes & Yes & Yes & Yes & Yes \\
Month FE & Yes & Yes & Yes & Yes & Yes & Yes & Yes & Yes \\
$\begin{array}{l}\text { Observations } \\
\text { Log }\end{array}$ & 3,159 & 2,037 & 1,122 & 3,159 & 1,630 & 994 & 636 & 1,630 \\
likelihood & -1503.54 & -968.75 & -530.32 & -1503.42 & -775.07 & -472.01 & -300.18 & -775.04 \\
\hline
\end{tabular}

Note: The table reports fractional logit regressions with robust standard errors. We include Field partner and month FE effects. We also included a dummy for loans with no field partner and two dummies for repayment interval but do not report them for the ease of presentation. $* * *$ significant at $1 \%$; ** significant at $5 \%$; significant at $10 \%$

Although the results from our empirical data support our prediction regarding the asymmetric beauty effects of male and female donors, it is important to replicate the results in a controlled setting. Therefore, we ran an experiment to provide further support for $\mathrm{H} 1$ and $\mathrm{H} 2$.

\section{Experimental study}

To test our hypotheses, we employed a 2 (attractiveness: high vs. low) x 2 (donor gender: male vs. female) x 2 (recipient gender: male vs. female) between-participants design. We recruited 500 participants on Amazon's MTurk, and 498 participated in our experiment ( 254 females; $M_{\text {age }}=30.53$ ). We used two images of each of the male and female recipient. Previous research suggests that face symmetry, color, and texture are related to perceived attractiveness (Jones et al. 2004; Zaatari et al. 2009). Following prior research, we chose one male and one female target and used computer graphics to manipulate attractiveness to manipulate facial attractiveness.

In the questionnaire, we first introduced donationbased crowdfunding platforms and provided participants with a campaign that was similar to the campaigns on real crowdfunding platforms. The target recipient differed across four conditions with two aspects, gender (i.e., male or female) and attractiveness (i.e., more or less attractive). After participants reviewed the campaign, they first indicated to what extent they would be willing to donate for the target recipient ("how likely would you be to donate to this recipient"; 1 = very unlikely, 7 = very likely). Then, participants indicated how much they would be willing to donate. To make their donation decision more realistic, we informed participants that some of the participants of this experiment would receive a bonus (\$.50 USD) and then asked them to indicate what percentage of the bonus they would donate for the recipient.

We proposed that male donors are likely to donate more to more attractive recipients due to their intuitive preference toward beauty. To test this underlying mechanism of males' larger, we asked participants to indicate how much they like the recipient as a person [47] on a 7-point scale. Different from male donors, female donors are expected to perceive less neediness from attractive recipients and reduce their donation. To test this decreased donation to attractive recipients, we measured perceived neediness using three items (i.e., "The recipient has a severe need," "The recipient has a pressing need to be sponsored," "The recipient requires assistance now"; Fisher and Ma 2014). Although these two are our proposed mechanisms, prior research suggests the effectiveness of their contributions as a determinant of charitable giving (Bekkers and Wiepking 2011). That is, individuals tend to engage in philanthropic behavior when they consider that their contributions more effective (Bekkers and Wiepking 2011). Considering that compared with women, men tend to men tend to give for utilitarian purposes [55], men may be willing to donate more for attractive recipients perceiving them to be more socially competent than less attractive recipients. We thus additionally measured efficacy using three items (i.e., "If the disease can be cured, how likely do you think the recipient will lead a happy life," "If the disease can be cured, how likely do you think the recipient will experience self-fulfillment," "If the disease can be cured, how likely do you think the recipient will be successful in chosen occupation"; Dion et al 1987). Last, participants provided their gender and age.

We first checked our manipulation of attractiveness. Supporting our manipulation, attractiveness has a significant main effect $(F(1,496)=59.46, \mathrm{p}<.001)$. Participants in the high attractiveness condition perceived the target recipients more attractive $(M=$ 4.98) that the participants in the low attractiveness condition did $(M=3.87)$. Interestingly, we also found a significant main effect of donors' gender $(F(1,496)=$ $4.02 ; p=.045)$. That is, male participants perceived the recipients slightly more attractive $(M=4.57)$ than female participants did $(M=4.26)$. However, when we separated our data by each gender of the donors, we found only a significant main effect of attractiveness and did not find any significant interaction effects. This suggests that participants evaluated the attractiveness of the recipient as we manipulated, although males tended to evaluate others more attractive relative to females did in this experiment. 
We then ran two separate three-way ANOVAs to test our hypotheses. We omit the results because of the page limit. A three-way ANOVA using donation intention as the dependent variable showed a significant three-way interaction $(F(1,490)=4.68, p=.031)$, suggesting that the beauty effect for male and female donors differs depending on the gender of the target recipient. We did not find a significant difference for the male recipient $(F s<1)$. On the other hand, for the female recipient, we found a significant interaction effect of attractiveness and donors' gender $(F(1,242)=12.41, p<.01)$. Specifically, male donors were more likely to give to more attractive female recipient $(M=4.84)$ than the less attractive recipient $(M=3.59)$. In contrast, female donors were less likely to give to the attractive recipient $(M=3.63)$ than the less attractive female recipient $(M=$ 3.93). These results support both $\mathrm{H} 1$ and $\mathrm{H} 2$.
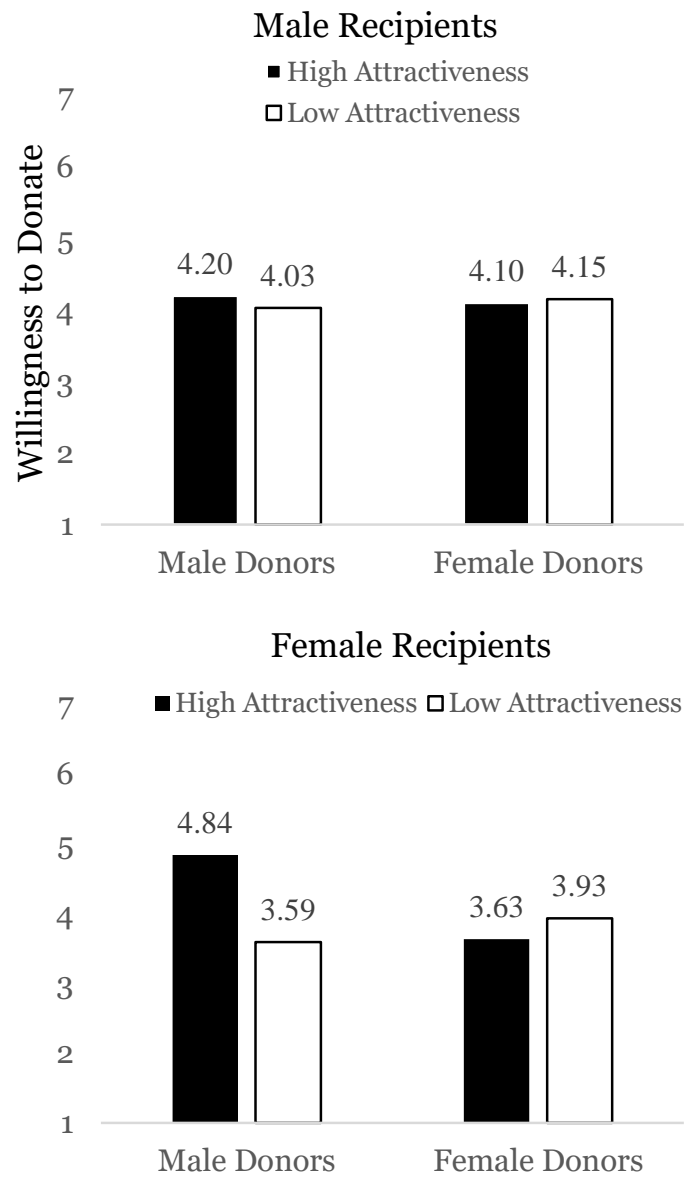

Figure 1. Gender Differences in Donation Intention to Male versus Female Recipients

The other three-way ANOVA using donation amount as the dependent variable showed similar patterns. We found a significant 3-way interaction $(F(1$, $490)=4.98, p=.026)$. Consistent with the results of donation intention, beauty effect on donation amount occurs only for female recipients not for male recipients, confirming H2. More important, male donors tended to give a larger amount to the more attractive female recipient $(M=48.12)$ than the less attractive female recipient $(M=35.76 ; F(1,242)=9.40, p<.01)$. However, female donor tended to give a smaller amount to the more attractive female recipient $(M=29.84)$ than the less attractive female recipient $(M=45.60)$. Therefore, our results for both donation intention and donation amount support our hypotheses.

\section{Conclusion}

This research examines the effect of physical attractiveness of recipients on donation decisions in a prosocial microlending market by combining both the archival data analysis and a controlled experiment. We found that physical attractiveness of female recipients matters to donors but in a rather complex way. More attractive female recipients tend to have a larger share of male donors, implying that male (female) donors are more (less) favorable toward those recipients. On the other hand, the physical attractiveness of male recipients did not change the composition significantly. Consistent with this empirical results, our experiment revealed that male donors are more generous to more attractive female recipients than less attractive recipients. In contrast, female donors are less generous to more attractive females than less attractive peers.

Our findings have several theoretical implications. First, we provide comprehensive evidence of the role of recipients' beauty in donation-based crowdfunding. While extant studies examine the effect of beauty in P2P lending and traditional funding, we know little about how the beauty will affect donation decisions $[9,43]$. This is important because investors in those markets should have strong financial incentives, whereas donors in our study have prosocial helping behaviors. Different incentives and motivations prevent us from generalizing prior findings. Actually, our findings are rather different from those in prior studies. We show that the beauty effect is rather complex depending on the gender of recipients and donors. Second, despite an increasing number of studies showing the beauty effect, most of the studies highlight the beauty premium effect. Although recent studies suggest some boundary conditions of the beauty premium effect, the beauty discount effect has been rarely examined and reported in the literature [23]. This study highlights that female recipients may not be more favorable toward more attractive female recipients. This is a significant finding because the beauty premium effect may not be always guaranteed. Along with an on-going debate of whether the beauty premium is taste-based or statistical discrimination [49], 
our study suggests that researchers should examine the beauty effect more carefully.

Our study also provides several practical implications for recipients and platform providers. Recipients can better understand how information cues including their profile images affect donation decisions. Female recipients may want to be more careful in describing their donation requests. Given the difficulty of manipulating their physical attractiveness, less competent would aim to attract female donors by using altruistic appeals. On the other hand, competent recipients can harvest benefits from their physical attractiveness by targeting male donors. For platform providers, our study suggests that they should be careful in posting profile images. Based on our findings, a certain portion of recipients can get a disadvantage from the displayed images. Thus, they need to assess this policy more comprehensively and provide proper tools to help those recipients get less disadvantaged. Furthermore, if this policy distorts funding toward riskier recipients, they may reconsider this policy.

\section{References}

1. Ai, W., Chen,R., Chen,Y., Mei,Q., and Phillips,W. Recommending teams promotes prosocial lending in online microfinance. Proceedings of the National Academy of Sciences of the United States of America, 113:52, (Dec 27, 2016), 14944-14948.

2. Allison, T.H., Davis,B.C., Short,J.C., and Webb,J.W. Crowdfunding in a prosocial microlending environment: Examining the role of intrinsic versus extrinsic cues. Entrepreneurship Theory and Practice, 39:1, (2015), 53-73.

3. Andreoni, J. Giving with impure altruism: Applications to charity and ricardian equivalence. Journal of Political Economy, 97:6, (1989), 1447-1458.

4. Bak, P.M. Sex differences in the attractiveness halo effect in the online dating environment. Journal of Business and Media Psychology, 1:1, (2010), 1-7.

5. Bar-Tal, D., and Saxe,L. Physical attractiveness and its relationship to sex-role stereotyping. Sex Roles, 2:2, (1976), 123-133.

6. Batson, C.D., and Shaw,L.L. Evidence for altruism: Toward a pluralism of prosocial motives. Psychological Inquiry, 2:2, (1991), 107-122.

7. Bekkers, R., and Wiepking,P. A literature review of empirical studies of philanthropy: Eight mechanisms that drive charitable giving. Nonprofit and Voluntary Sector Quarterly, 40:5, (2011), 924-973.

8. Bernard, J. The good-provider role: Its rise and fall. American Psychologist, 36:1, (1981), 1.

9. Brooks, A.W., Huang,L., Kearney,S.W., and Murray,F.E. Investors prefer entrepreneurial ventures pitched by attractive men. Proceedings of the National Academy of Sciences of the United States of America, 111:12, (2014), 4427-4431.

10. Broverman, I.K., Vogel,S.R., Broverman,D.M., Clarkson,F.E., and Rosenkrantz,P.S. Sex-role stereotypes: A current appraisal. Journal of Social Issues, 28:2, (1972), 5978.

11. Burtch, G., and Chan,J. Investigating the relationship between medical crowdfunding and personal bankruptcy in the united states. Available at SSRN: Https://Ssrn.Com/abstract=2676821, (2017), .

12. Burtch, G., Ghose,A., and Wattal,S. Cultural differences and geography as determinants of online pro-social lending. Management Information Systems Quarterly, 38:3, (2014), 773-794.

13. An empirical examination of the antecedents and consequences of contribution patterns in crowd-funded markets. Information Systems Research, 24:3, (2013), 499519.

14. Chang, C., and Lee,Y. The 'I' of the beholder: How gender differences and self-referencing influence charity advertising. International Journal of Advertising, 30:3, (2011), 447-478.

15. Croson, R., and Gneezy,U. Gender differences in preferences. Journal of Economic Literature, 47:2, (2009), 448-474.

16. Cryder, C., Botti,S., and Simonyan,Y. The charity beauty premium: Satisfying Donors" "Want" versus "Should" desires. Journal of Marketing Research, 54:4, (2017), 605-618.

17. Diamond, W.D., and Kashyap,R.K. Extending models of prosocial behavior to explain university alumni contributions. Journal of Applied Social Psychology, 27:10, (1997), 915-928. 18. Dion, K., Berscheid,E., and Walster,E. What is beautiful is good. Journal of Personality and Social Psychology, 24:3, (1972), 285.

19. Eagly, A.H., Ashmore,R.D., Makhijani,M.G., and Longo,L.C. What is beautiful is good, but...: A meta-analytic review of research on the physical attractiveness stereotype. Psychological Bulletin, 110:1, (1991), 109.

20. Eagly, A.H., and Crowley,M. Gender and helping behavior: A meta-analytic review of the social psychological literature. Psychological Bulletin, 100:3, (1986), 283.

21. Feingold, A. Good-looking people are not what we think. Psychological Bulletin, 111:2, (1992), 304.

22. Fink, B., and Penton-Voak,I. Evolutionary psychology of facial attractiveness. Current Directions in Psychological Science, 11:5, (2002), 154-158.

23. Fisher, R.J., and Ma,Y. The price of being beautiful: Negative effects of attractiveness on empathy for children in need. Journal of Consumer Research, 41:2, (2014), 436-450. 24. Galak, J., Small,D., and Stephen,A.T. Microfinance decision making: A field study of prosocial lending. Journal of Marketing Research, 48:SPL, (2011), S130-S137.

25. Hamermesh, D.S., and Biddle,J.E. Beauty and the Labor Market. American Economic Review, 84:5, (1993), 11741194.

26. Harbaugh, W.T., Mayr,U., and Burghart,D.R. Neural responses to taxation and voluntary giving reveal motives for charitable donations. Science (New York, N.Y.), 316:5831, (Jun 15, 2007), 1622-1625.

27. Hayden, B.Y., Parikh,P.C., Deaner,R.O., and Platt,M.L. Economic principles motivating social attention in humans. Proceedings.Biological Sciences, 274:1619, (Jul 22, 2007), 1751-1756. 
28. Jenq, C., Pan,J., and Theseira,W. Beauty, weight, and skin color in charitable giving. Journal of Economic Behavior \& Organization, 119:(2015), 234-253. 29. Kaplan, R.M. Is beauty talent? sex interaction in the attractiveness halo effect. Sex Roles, 4:2, (1978), 195-204. 30. Landry, C.E., Lange,A., List,J.A., Price,M.K., and Rupp,N.G. Toward an understanding of the economics of charity: Evidence from a field experiment. The Quarterly Journal of Economics, 121:2, (2006), 747-782.

31. Landy, D., and Sigall,H. Beauty is talent: Task evaluation as a function of the performer's physical attractiveness. Journal of Personality and Social Psychology, 29:3, (1974), 299-304.

32. Langlois, J.H., Kalakanis,L., Rubenstein,A.J., Larson,A., Hallam,M., and Smoot,M. Maxims or myths of beauty? A meta-analytic and theoretical review. Psychological Bulletin, 126:3, (2000), 390.

33. Levy, B., Ariely,D., Mazar,N., Chi,W., Lukas,S., and Elman,I. Gender differences in the motivational processing of facial beauty. Learning and Motivation, 39:2, (2008), 136145.

34. Meer, J., and Rigbi,O. The effects of transactions costs and social distance: Evidence from a field experiment. The BE Journal of Economic Analysis \& Policy, 13:1, (2013), 271-296.

35. Mims, P.R., Hartnett,J.J., and Nay,W.R. Interpersonal attraction and help volunteering as a function of physical attractiveness. The Journal of Psychology, 89:1, (1975), 125131.

36. Min, S., and Levina,N. Charity Or Investment: Linguistic Features of Identifiable Victim Effect in Microlending, In Anonymous 2017,

37. Mohammadi, A., and Shafi,K. Gender differences in the contribution patterns of equity-crowdfunding investors. Small Business Economics, 50:2, (2018), 275-287.

38. O'Doherty, J., Kringelbach,M.L., Rolls,E.T., Hornak,J., and Andrews,C. Abstract reward and punishment representations in the human orbitofrontal cortex. Nature Neuroscience, 4:1, (2001), 95-102.

39. Olson, I.R., and Marshuetz,C. Facial attractiveness is appraised in a glance. Emotion, 5:4, (2005), 498-502. 40. Pope, D.G., and Sydnor,J.R. What's in a picture? evidence of discrimination from prosper. com. Journal of Human Resources, 46:1, (2011), 53-92.

41. Radley, A., and Kennedy,M. Reflections upon charitable giving: A comparison of individuals from business, 'manual'and professional backgrounds. Journal of Community \& Applied Social Psychology, 2:2, (1992), 113129.

42. Raihani, N.J., and Smith,S. Competitive helping in online giving. Current Biology, 25:9, (2015), 1183-1186.
43. Ravina, E. Love \& loans: The effect of beauty and personal characteristics in credit markets.

Https://Papers.Ssrn.Com/Sol3/Papers.Cfm?Abstract_id=110 7307, (2012)

44. Reimann, M., Zaichkowsky,J., Neuhaus,C., Bender,T., and Weber,B. Aesthetic package design: A behavioral, neural, and psychological investigation. Journal of Consumer Psychology, 20:4, (2010), 431-441.

45. Rhodes, G. The evolutionary psychology of facial beauty. Annu.Rev.Psychol., 57:(2006), 199-226.

46. Ruble, T.L. Sex stereotypes: Issues of change in the 1970s. Sex Roles, 9:3, (1983), 397-402.

47. Sigall, H., and Aronson,E. Liking for an evaluator as a function of her physical attractiveness and nature of the evaluations. Journal of Experimental Social Psychology, 5:1, (1969), 93-100.

48. Staub, E., and Baer,R.S. Stimulus characteristics of a sufferer and difficulty of escape as determinants of helping. Journal of Personality and Social Psychology, 30:2, (1974), 279-284.

49. Stinebrickner, T.R., Stinebrickner,R., and Sullivan,P.J.

Beauty, job tasks, and wages: A new conclusion about employer taste-based discrimination. NBER Technical Working Paper (no. 24479), (2018), .

50. Tsukiura, T., and Cabeza,R. Remembering beauty: Roles of orbitofrontal and hippocampal regions in successful memory encoding of attractive faces. NeuroImage, 54:1, (2011), 653-660.

51. Utida, S., Kamiya,M., Johnson,D.W., and Bern,H.A. Effects of freshwater adaptation and of prolactin on sodiumpotassium-activated adenosine triphosphatase activity in the urinary bladder of two flounder species. The Journal of Endocrinology, 62:1, (Jul, 1974), 11-14.

52. Van der Graaff, J., Branje,S., De Wied,M., Hawk,S., Van Lier,P., and Meeus,W. Perspective taking and empathic concern in adolescence: Gender differences in developmental changes. Developmental Psychology, 50:3, (2014), 881.

53. Vuilleumier, P. Faces call for attention: Evidence from patients with visual extinction. Neuropsychologia, 38:5, (2000), 693-700.

54. Wagner, C., and Wheeler,L. Model, need, and cost effects in helping behavior. Journal of Personality and Social Psychology, 12:2, (1969), 111-116.

55. Webster, C., and Nottingham,L. Gender Differences in the Motivations for Gift Giving, In Anonymous American Marketing Association. Conference Proceedings, American Marketing Association, 2000, pp. 272.

56. Willer, R., Wimer,C., and Owens,L.A. What drives the gender gap in charitable giving? lower empathy leads men to give less to poverty relief. Social Science Research, 52:(2015), 83-98. 